\title{
Selective Solubilization of Bovine Milk Fat Globule Membrane Proteins with Guanidine Hydrochloride and Disposition of Some of the Proteins
}

\author{
Makoto SHImIzU, Choemon KanNo* and Kunio YamaUCHI \\ Department of Agricultural Chemistry, The University of Tokyo, \\ Bunkyo-ku, Tokyo 113, Japan \\ Received June 12, 1978
}

\begin{abstract}
Guanidine hydrochloride $(\mathrm{GuHCl})$ solubilized $35 \%$ and $60 \%$ of the constituent proteins of isolated milk fat globule membrane (MFGM) at the concentrations of $1.8 \mathrm{M}$ and $6.0 \mathrm{M}$, respectively. The hydrophilic amino acid and carbohydrate contents of the soluble fractions were slightly greater than those of the insoluble fractions. Sodium dodecylsulfate-polyacrylamide gel electrophoresis revealed that the solubilization was highly selective. Polypeptides such as $\mathrm{CB}-7+8,12,13,14$ and 15 were easily solubilized with $1.8 \mathrm{M} \mathrm{GuHCl}$, and PAS-1, 2, 3, 4 and $\mathrm{CB}-1$ required $3 \sim 6 \mathrm{M} \mathrm{GuHCl}$ to attain their complete solubilization, while $\mathrm{CB}-5$ and 6 were highly insoluble.

Selective release of the proteins from the native MFGM (washed cream) by $\mathrm{GuHCl}$ extraction $(0 \sim 2.1 \mathrm{M})$ was also observed; i. e., some minor polypeptides, such as $\mathrm{CB}-12,13,14,15$ and 16 were readily solubilized with $0.6 \sim 1.2 \mathrm{M} \mathrm{GuHCl}$, and a major glycoprotein, $\mathrm{CB}-7+8$ (PAS-6+7), was solubilized with $1.8 \sim 2.1 \mathrm{M} \mathrm{GuHCl}$. The results suggested that these polypeptides were peripheral proteins and bound with other components of the membrane by relatively weak interaction. On the other hand, the proteins remaining in the cream fraction seem to bind with other components of the membrane by relatively strong interaction.
\end{abstract}

Milk fat globule membrane (MFGM) has been investigated from various viewpoints by many researchers. The general profiles of the constituent proteins of MFGM on sodium dodecyl sulfate-polyacrylamide gel electrophoresis (SDS-PAGE) were reported by Kobylka and Carraway, ${ }^{1)}$ Anderson et al., ${ }^{2}$ Kitchen, ${ }^{3,}$ Mather and Keenan, ${ }^{4)}$ Mangino and Brunner, ${ }^{5}$ and Shimizu et al. ${ }^{6}$ ) The variations of MFGM proteins also have been investigated with respect to the lactation period, ${ }^{7 \sim 9} \operatorname{diet}^{10\}}$ and other factors. ${ }^{11,12}$ In addition, isolation and partial characterization of some constituent proteins have been attempted..$^{13 \sim 16)}$ Through these studies it has been revealed that MFGM is constructed of a number of proteins remarkably different in size and chemical properties. The mode of interaction of these proteins with the membrane matrix has been reported in a few papers. Mather et al. ${ }^{4,17)}$ suggested that MFGM proteins were asymmetrically arranged

* Present address: Faculty of Agriculture, Utsunomiya University, Mine-machi, Utsunomiya 120 , Japan. in the membrane and some proteins were likely to be extrinsic polypeptides, based on the results of proteolytic experiments, ${ }^{125}$ I-labelling and extraction experiments with dilute salts or detergent solutions.

Guanidine hydrochloride ( $\mathrm{GuHCl}$ ), a chaotropic agent, is known to be effective in breaking some interactions between lipids and proteins, and has been utilized for solubilization of biological membranes ${ }^{18 \sim 20}$ and lipoproteins. $^{21,22)}$

The present study was undertaken to obtain further information on the interaction of MFGM proteins with the membrane matrix.

\section{MATERIALS AND METHODS}

Preparation of washed cream and isolated MFGM. Raw cream was prepared from fresh uncooled milk of Holstein cows, and washed three times with $4 \sim 5$ fold quantities of deionized water at $35 \sim 40^{\circ} \mathrm{C}$ on a cream separator.

MFGM was isolated from washed cream by churning in accordance with the procedure described previously. ${ }^{23)}$ 
Solubilization of MFGM and washed cream by $\mathrm{GuHCl}$. $\mathrm{GuHCl}$ of reagent grade was purchased from Wako Pure Chemicals Co., Ltd. To an aqueous suspension of MFGM in $20 \mathrm{~mm}$ phosphate buffer ( $\mathrm{pH} 7.0$ ) was added solid or $6 \mathrm{M} \mathrm{GuHCl}$ to produce a final concentration of $0.6 \sim 6 \mathrm{M}$. The mixture $(2 \sim 4 \mathrm{mg}$ protein $/ \mathrm{ml})$ was incubated at $37^{\circ} \mathrm{C}$ for $2 \mathrm{hr}$ and centrifuged at $40,000 \mathrm{~g}$ for $2 \mathrm{hr}$ at $4^{\circ} \mathrm{C}$. The cloudy suspension was separated into a clear supernatant and a precipitate by centrifugation. The supernatant was dialyzed against $10 \mathrm{~mm}$ phosphate buffer containing $1 \%$ SDS and $1 \%$ 2-mercaptoethanol, and subjected to SDS-PAGE. Aliquots of the samples were dialyzed against deionized water, freeze-dried and subjected to chemical analyses. The precipitate was redispersed into $10 \mathrm{~mm}$ phosphate buffer containing $1 \%$ SDS and $1 \% 2$-mercaptoethanol, and solubilized by heating at $100^{\circ} \mathrm{C}$ for $1 \sim 2 \mathrm{~min}$. The solution was then centrifuged to remove lipid-SDS complexes and subjected to SDS-PAGE.

To washed cream in $20 \mathrm{~mm}$ phosphate buffer $(\mathrm{pH}$ 7.0) was added $6 \mathrm{M} \mathrm{GuHCl}$ solution to a final concentration of $0 \sim 2.1 \mathrm{M}$. The mixtures $(1 \sim 2 \mathrm{mg}$ protein $/ \mathrm{ml})$ were incubated and centrifuged as described above. After centrifugation, a packed cream layer, clear supernatant and precipitate were recovered separately and treated as described above.

$S D S$-polyacrylamide gel electrophoresis ( $S D S-P A G E)$. SDS-PAGE was carried out in accordance with the procedure of Weber and Osborn ${ }^{24)}$ using $10 \%$ acrylamide gel.

Chemical analysis. Protein was determined by the procedure of Lowry et al. ${ }^{25)}$ using bovine serum albumin (Seikagaku Kogyo Co., Ltd.) as standard.

Amino acid analysis was performed with a Nippon Densi JLC-6AH amino acid analyzer. Protein was hydrolyzed in $6 \mathrm{~N} \mathrm{HCl}$ at $110^{\circ} \mathrm{C}$ for $20 \mathrm{hr}$ in evacuated and sealed Pyrex tubes.

Sialic acid was determined by the procedure of Warren $^{26)}$ after hydrolysis with $0.1 \mathrm{~N} \mathrm{H}_{2} \mathrm{SO}_{4}$ for $1 \mathrm{hr}$ at $80^{\circ} \mathrm{C}$. N-Acetylneuraminic acid was used as standard. Hexoses were determined in accordance with Dubois et al. ${ }^{27)}$ employing a mixture of galactose and mannose (1:1) as standard.

Phospholipid was determined in terms of phosphate by the procedure of Rouser et al. ${ }^{29)}$

\section{RESULTS}

\section{Solubilization of $\mathrm{MFGM}$ proteins by $\mathrm{GuHCl}$}

The isolated MFGM was observed to be partially solubilized with $6 \mathrm{~m} \mathrm{GuHCl}$. Solubilization of MFGM proteins was enhanced with the increase of $\mathrm{GuHCl}$ concentration as shown in Fig. 1. About 35\% of total protein

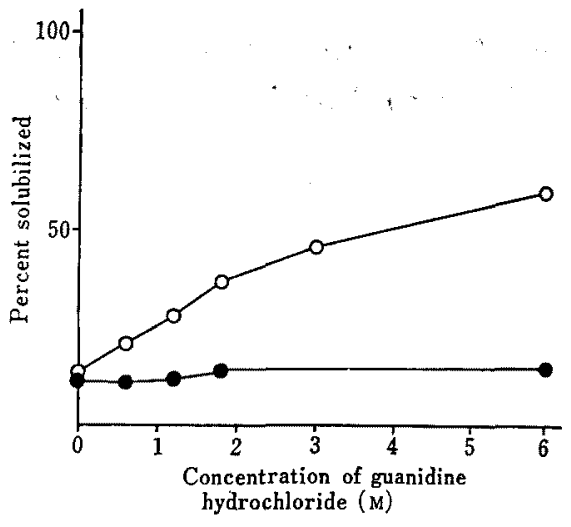

FIG. 1. Effect of Concentration of Guanidine Hydrochloride on Solubilization of Protein and Phospholipid in the Isolated MFGM.

$\mathrm{O}$, protein; $\bullet$, phospholipid.

was solubilized with $1.8 \mathrm{M} \mathrm{GuHCl}$ and $60 \%$ with $6 \mathrm{M} \mathrm{GuHCl}$. No significant amount of phospholipid was solubilized with $0.6 \sim 6 \mathrm{M}$ $\mathrm{GuHCl}$ (Fig. 1).

\section{Chemical composition of the solubilized proteins}

Chemical composition of the fraction solubilized with $6 \mathrm{M} \mathrm{GuHCl}$ was compared with that of the total MFGM protein (Tables I and II).

Amino acid composition of the total MFGM was in good agreement with those reported previously. ${ }^{29}$ ) No remarkable differences were observed between the amino acid compositions of the total MFGM and $6 \mathrm{M} \mathrm{GuHCl}$-soluble fraction except that the latter was relatively rich in some hydrophilic amino acids (Asp and Thr) and poor in some hydrophobic amino acids (Val and Leu). The mole percentages of total hydrophilic amino acids (Lys, His, Arg, Asp, Glu, Thr and Ser) in the total MFGM and $6 \mathrm{M} \mathrm{GuHCl}$-soluble fraction were 46.8 and 50.2 , respectively.

The contents of sialic acid and hexoses in $6 \mathrm{~m}$ GuHCl-soluble fraction were slightly higher than those in the total MFGM protein (Table II).

These results suggest that proteins solubilized with $6 \mathrm{M} \mathrm{GuHCl}$ have a more hydrophilic property than the residual proteins. 
Table I. Amino Acid Compositions of Total MFGM AND 6 M GuHCl-SOluble Fraction Values are expressed in mole $\%$ of total amino acids. Analysis was based on $20 \mathrm{hr}$ hydrolysis. Threonine and serine were not corrected.

\begin{tabular}{lcc}
\hline Amino acid & Total MFGM & $\begin{array}{c}\text { 6 M GuHCl- } \\
\text { soluble fraction } \\
\text { of MFGM }\end{array}$ \\
\hline Lysine & 5.6 & 4.9 \\
Histidine & 2.3 & 2.6 \\
Arginine & 4.5 & 4.2 \\
Aspartic acid & 9.0 & 11.0 \\
Glutamic acid & 11.6 & 11.6 \\
Threonine & 6.4 & 8.5 \\
Serine & 7.4 & 7.4 \\
Proline & 6.9 & 5.0 \\
Glycine & 7.5 & 9.0 \\
Alanine & 6.4 & 6.0 \\
1/2 Cystine & 0.8 & 1.4 \\
Valine & 6.5 & 5.0 \\
Methionine & 3.1 & 2.6 \\
Isoleucine & 4.4 & 4.5 \\
Leucine & 10.0 & 8.7 \\
Tyrosine & 3.0 & 3.3 \\
Phenylalanine & 4.8 & 4.5 \\
Tryptophan & & not determined \\
\hline
\end{tabular}

Table II. Carbohydrate Contents of Total MFGM and GuHCl-soluble Fraction

\begin{tabular}{lll}
\hline & $\begin{array}{c}\text { Sialic acid } \\
\mathrm{mg} / 100 \mathrm{mg} \text { protein }^{\mathrm{a}}\end{array}$ \\
\hline Total MFGM & 2.16 & 6.95 \\
$6 \mathrm{M} \mathrm{GuHCl}$-soluble & 3.20 & 8.60 \\
$1.8 \mathrm{M}-$ & 2.62 & N. D. \\
$0 \mathrm{M}-$ & 2.50 & N. D. \\
\hline
\end{tabular}

a Determined by the procedure of Lowry et al. ${ }^{25)}$

b Not determined.

\section{Selectivity in the solubilization of polypeptides}

SDS-PAGE patterns of GuHCl-soluble and -insoluble proteins are shown in Fig. 2. CB$7+8,12,13,14$ (I) and 15 (II) were almost completely solubilized with a relatively low concentration $(1.2 \sim 1.8 \mathrm{M})$ of $\mathrm{GuHCl}$. CB$7+8$ (PAS-6+7), a major glycoprotein of MFGM, was intensely stained with periodic acid-Schiff reagent. Other major glycoproteins, PAS-1, 2, 3 and 4 (CB-4), and a major polypeptide, $\mathrm{CB}-1$, were solubilized only partly with a low concentration $(1.2 \sim 1.8 \mathrm{M})$ of $\mathrm{GuHCl}$, but completely with a higher concentration $(3 \sim 6 \mathrm{M})$ of $\mathrm{GuHCl}$. Two major poly-

\section{$\mathrm{CB}$}

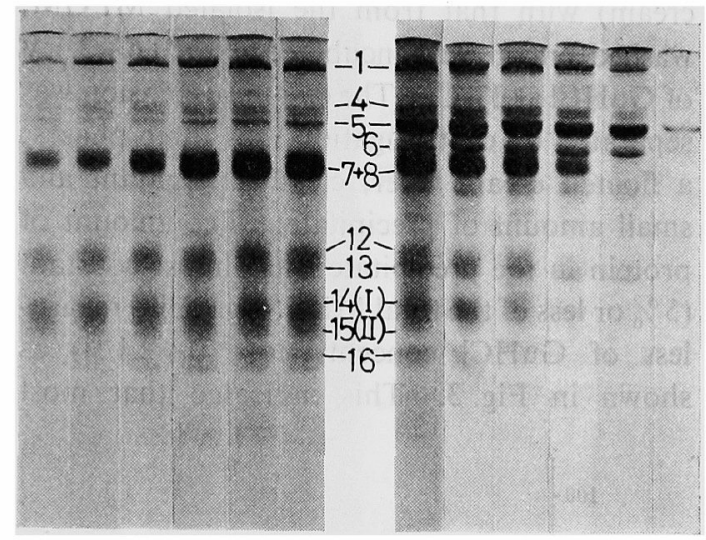

PAS

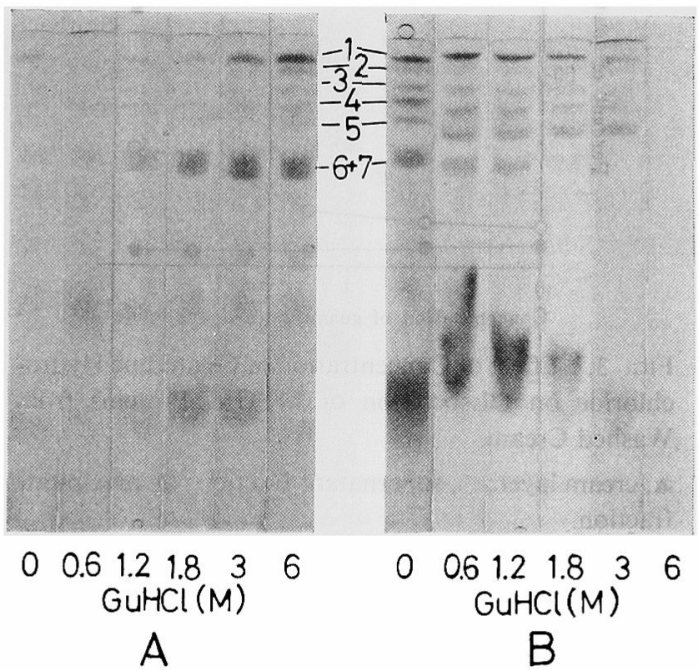

FIG. 2. SDS-PAGE Patterns of Guanidine Hydrochloride-soluble and -insoluble Proteins.

A) Soluble fraction, B) insoluble fraction. CB, stained with Coomassie blue $\mathrm{R}-250$ for protein; PAS, stained with periodic acid-Schiff reagent for carbohydrate.

peptides, CB-5 (PAS-5) and 6, were not completely solubilized even with $6 \mathrm{M} \mathrm{GuHCl}$ and were concentrated in the precipitates. Mather et al. ${ }^{17)}$ who employed $6 \mathrm{M} \mathrm{GuHCl}$ for the solubilization of MFGM proteins also observed such selectivity.

Release of the MFGM proteins from washed cream

In order to compare the solubilization of 
polypeptides from the intact MFGM (washed cream) with that from the isolated MFGM, washed cream was incubated with $0.6 \sim 2.1 \mathrm{M}$ of $\mathrm{GuHCl}$ at $37^{\circ} \mathrm{C}$. The cream suspension was separated by centrifugation into three phases; a floated cream layer, clear supernatant and small amount of precipitate. The amount of protein in the precipitate was almost constant (5\% or less of the total MFGM protein) regardless of $\mathrm{GuHCl}$ concentration $(0 \sim 2.1 \mathrm{M})$ as shown in Fig. 3. This indicated that most

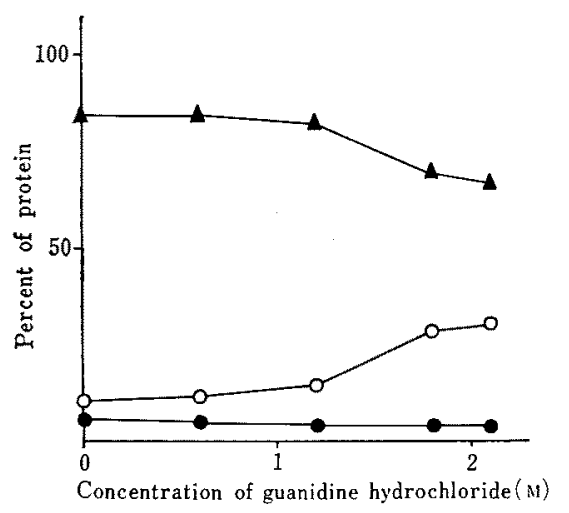

FIG. 3. Effect of Concentration of Guanidine Hydrochloride on Dissociation of MFGM Proteins from Washed Cream.

$\Delta$, cream layer; $\bigcirc$, supernatant fraction; $\bullet$, precipitate fraction.

GuHCl-insoluble proteins were not released from washed cream by the action of $\mathrm{GuHCl}$ at $0.6 \sim 2.1 \mathrm{M}$. The precipitate fraction obtained herein, therefore, is likely to be MFGM fragments released from the fat globule surface into an aqueous phase by disruption during the washing or mixing process. On the other hand, the amount of the solubilized protein in the supernatant fraction gradually increased with the concentration of $\mathrm{GuHCl}$. Most remarkable change was observed between $1.2 \mathrm{M}$ and $1.8 \mathrm{M} \mathrm{GuHCl}$ treatments as shown in Fig. 3 . This indicated that much of $\mathrm{GuHCl}$-soluble proteins was released from milk fat globule surface by $1.8 \mathrm{M} \mathrm{GuHCl}$, a half of which was not released by $1.2 \mathrm{M}$. Oiling-off of the cream was not observed when it was treated with such low concentrations of $\mathrm{GuHCl}$, but exceeding oiling-off was observed upon treatment with $6 \mathrm{M} \mathrm{GuHCl}$.

SDS-PAGE patterns of the precipitate and supernatant fractions are shown in Fig. 4-A,B. Remarkable changes in composition of proteins were observed in the supernatant fractions when the concentration of $\mathrm{GuHCl}$ increased, while the changes in the precipitate fractions were slight. Some minor polypeptides, such as $\mathrm{CB}$ $12,13,14$ (I), 15 (II) and 16, were readily solubilized with $0.6 \mathrm{M}$ or $1.2 \mathrm{M} \mathrm{GuHCl}$. The major polypeptides such as $\mathrm{CB}-1,4$ (PAS-4), 5 (PAS5) and $7+8$ (PAS-6+7), however, were not solubilized from washed cream at these concentrations. CB-7+8 (PAS-6+7) was released from the fat globules with $1.8 \sim 2.1 \mathrm{M} \mathrm{GuHCl}$, but the other major proteins and glycoproteins still remained in the cream fraction (Fig. 4-C). These results suggest that the major glycoprotein, CB-7+8 (PAS-6+7), is a peripheral protein and binds the membrane with weaker interaction than the other major proteins.

Selectivities in the solubilization of proteins from the isolated MFGM and the washed cream were slightly different when a low concentration $(0.6 \sim 2.1 \mathrm{M})$ of $\mathrm{GuHCl}$ was employed. The major polypeptides other than CB$7+8$ were partly solubilized from the isolated MFGM but not from the washed cream. Such differences might reflect the increased fragility of the membrane after isolation processes and also the different states of location of membrane proteins in the washed cream and the isolated MFGM.

\section{DISCUSSION}

MFGM is considered to be derived from the plasma membrane of mammary secretory cell. $^{29}$ However, the origin of the individual constituent polypeptides of MFGM is still obscure. Mather and Keenan ${ }^{4}$ suggested the possibility that $\mathrm{CB}-7+8$ (band $15+16$ in their report) was adsorbed from milk serum since it was lost during the isolation process of MFGM. Furthermore, Kanno and Yama$u{ }^{3 i^{30}}$ found that some of the low molecular weight glycoproteins such as CB-I and II $(\text { PAS-IV and V) })^{6}$ have an identical antigenicity 


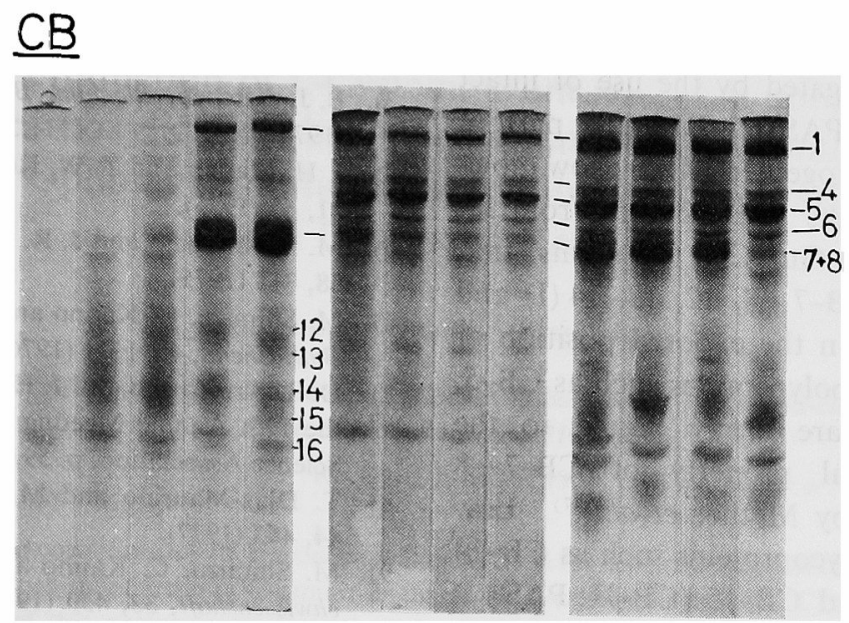

\section{$\underline{\text { PAS }}$}

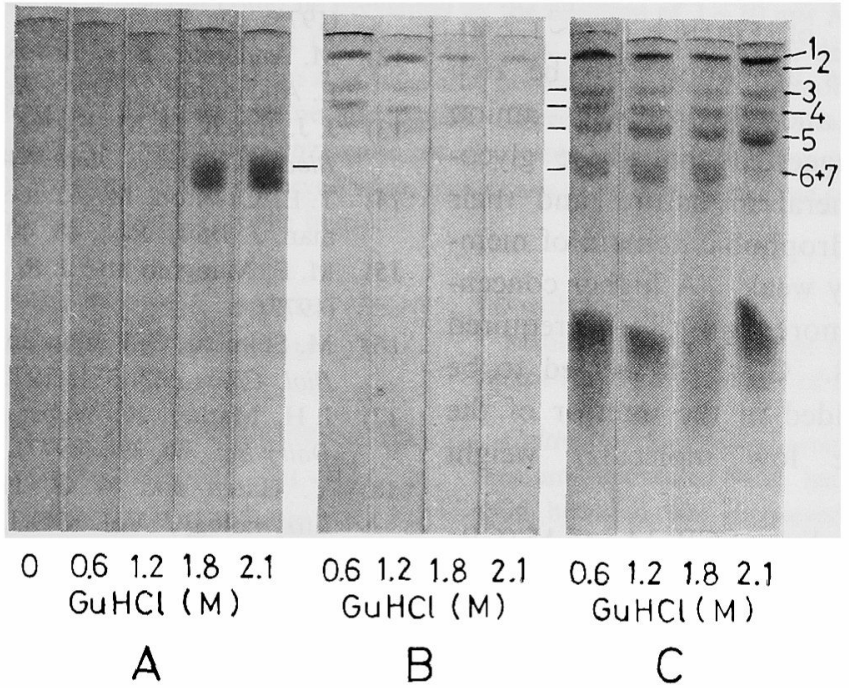

FIG. 4. SDS-PAGE Patterns of Released Proteins during Incubation of Washed Cream with Guanidine Hydrochloride $(0 \sim 2.1 \mathrm{M})$.
A) Proteins solubilized in the supernatant, B) proteins recovered as the precipitate fraction, C) proteins remaining in the cream layer. CB: Stained with Coomassie blue R-250 for protein, PAS: Stained with periodic acid-Schiff reagent for carbohydrate.

to the proteose-peptone fraction in whey. It is necessary to investigate the location of these proteins in MFGM in connection with their origin.

Increasing concentrations of $\mathrm{GuHCl}$ have been found to cause sequential solubilization of MFGM proteins. The solubilization was highly selective. $\mathrm{CB}-7+8$ and the low molecular weight polypeptides such as $\mathrm{CB}-12 \sim 15$ were readily solubilized with $6 \mathrm{M} \mathrm{GuHCl}$.
Polarity of the $\mathrm{GuHCl}$-soluble proteins was somewhat higher than that of the GuHClinsoluble proteins. However, such differences seemed to be insignificant. Therefore, the selectivity in the solubilization cannot be explained by the different polarities of the individual protein components. It may be related to difference among the proteins in strength or mode of interaction with other components of the membrane. 
Disposition of the proteins on the intact MFGM was investigated by the use of intact cream. $\mathrm{CB}-7+8$ (PAS-6+7) and a part of $\mathrm{CB}-1$ were released together with the low molecular weight proteins (CB-12 15) from fat globules by $1.8 \mathrm{M} \mathrm{GuHCl}$. It seems that proteins such as $\mathrm{CB}-7+8,12,13,14$ (I) and 15 (II) are located in the exposed position of MFGM, while the polypeptides such as $\mathrm{CB}-5$, 6 and PAS-1 $\sim 4$ are firmly bound to the MFGM. Peripheral property of $\mathrm{CB}-7+8$ was also reported by Mather et al. ${ }^{4,17}$, Low molecular weight glycoproteins such as $\mathrm{CB}-14$ (CB-I: PAS-IV) and CB-15 (CB-II: PAS-V) were released and solubilized easily from both washed cream and the isolated MFGM with low concentrations of $\mathrm{GuHCl}(0.6 \sim 1.2 \mathrm{M})$. These glycoproteins are known to be rich in carbohydrate and hydrophilic amino acids. ${ }^{6,23}$ It is suggested that these glycoproteins are peripheral in nature, and their interaction with hydrophobic domain of membrane matrix is very weak. A higher concentration of $\mathrm{GuHCl}$ (more than $1.8 \mathrm{M}$ ) is required to release $\mathrm{CB}-7+8$. $\mathrm{CB}-7+8$ seemed to be more firmly embedded in the interior of the MFGM than the low molecular weight proteins.

The very weak binding of CB-14 and 15 (CBI and II) on the globule surface suggests that either these glycoproteins are adsorbed onto MFGM from the milk serum or they are originally on MFGM and are released into the milk serum. The peripheral nature of CB $-7+8$ suggests that this glycoprotein is somewhat different in origin from the other major proteins of MFGM.

Acknowledgements, We are indebted to Dr.J. Kurisaki for his helpful suggestions and discussions. We also thank Miss S. Yamato for her assistance in the electrophoretic experiments.

This work was partly supported by a Grant from the Ministry of Education, the Government of Japan (Grant No. 247112).

\section{REFERENCES}

1) D. Kobylka and K. L. Carraway, Biochim. Biophys. Acta, 288, 282 (1972).
2) M. Anderson, T. Cawston and G. C. Cheeseman, Biochem. J., 139, 653 (1974).

3) B. J. Kitchen, Biochim. Biophys. Acta, 356, 257 (1974).

4) I. H. Mather and T. W. Keenan, J. Membr. Biol., 21, 65 (1975).

5) M. E. Mangino and J. R. Brunner, J. Dairy Sci., 58, 313 (1975).

6) M. Shimizu, C. Kanno and K. Yamauchi, Agric. Biol. Chem., 40, 1711 (1976).

7) D.S. Armstrong and I. H. Mather, Abstracts of the 72th Annual Meeting of the American Dairy Science Association, p. 59 (1977).

8) T. Diaz-Maurino and M. Nieto, J. Dairy Res,, 44, 483 (1977).

9) M. Shimizu, C. Kanno and K. Yamauchi, Milchwissenshaft, 33, 439 (1978).

10) M. Anderson, J. Dairy Sci., 57, 399 (1974).

11) R. E. Erwin and H. E. Randolph, ibid., 58, 9 (1975).

12) M. Anderson, B. E. Brooker, A. T. Andrews and E. Alichanidis, J. Dairy Res. 42, 401 (1975).

13) J. J. Basch, H. M. Farrel, Jr. and R. Greenberg, Biochim. Biophys. Acta, 448, 589 (1976).

14) T. E. Cawston, M. Anderson and G. C. Cheeseman, J. Dairy Res., 43, 401 (1976).

15) M. E. Mangino and J. R. Brunner, ibid., 60, 841 (1977).

16) M. Shimizu, C. Kanno and K. Yamauchi, Agric. Biol. Chem., 42, 981 (1978).

17) I. H. Mather, K. Weber and T. W. Keenan, J. Dairy Sci., 60, 394 (1977).

18) Y. Hatefi and W. G. Hanstein, "Methods in Enzymology," Vol. XXXI, ed. by S. Fleischer and L. Packer, Academic Press Inc., New York, 1974, p. 770 .

19) A. H. Maddy and P. G. Kelly, Biochim. Biophys. Acta, 241, 114 (1971).

20) T. L. Steck, ibid., 255, 553 (1972).

21) A. Ikai, J. Biochem., 77, 321 (1975).

22) J. Kurisaki and K. Yamauchi, ibid., 81, 443 (1977).

23) C. Kanno, M. Shimizu and K. Yamauchi, Agric. Biol. Chem., 39, 1835 (1975).

24) K. Weber and M. Osborn, J. Biol. Chem., 244, 4406 (1969).

25) O. H. Lowry, N. J. Rosebrough, A. L. Farr and R. J. Randall, ibid., 193, 265 (1951).

26) L. Warren, ibid, 234, 2971 (1959).

27) M. Dubois, K. A. Gilles, J. K. Hamilton, P. A. Rebers and F. Smith, Anal. Chem., 28, 350 (1956).

28) G. Rouser, A. N. Siakotos and S. Fleischer, Lipids, 1, 85 (1966).

29) S. Patton and T. W. Keenan, Biochim. Biophys. Acta, 415, 273 (1975).

30) C. Kanno and K. Yamauchi, Agric. Biol. Chem., 42, 1697 (1978). 